\title{
CONTRIBUIÇÕES DO ENSINO DE ARTE PARA PREVENÇÃO DA VIOLÊNCIA BULLYING
}

\author{
Gilcimara Juliana Gabriel ${ }^{1}$, Raul Aragão Martins ${ }^{2}$ \\ ${ }^{1}$ Mestre em Educação pela Universidade Estadual Paulista - UNESP, Campus de Marília. É professora PEB III de Arte \\ no município de Fartura-SP. ORCID: 0000-0002-8942-6395 E-mail: gilcimaragabriel@gmail.com \\ ${ }^{2}$ Livre-Docente em Psicologia da Educação pela Universidade Estadual Paulista - UNESP, Professor adjunto do \\ Departamento de Educação do Instituto de Biociências, Letras e Ciências Exatas - IBILCE, da Universidade Estadual \\ Paulista - UNESP, São José do Rio Preto, SP e do Programa de Pós-Graduação em Educação da Universidade \\ Estadual Paulista - UNESP, Marília, SP. ORCID: 0000-0001-6495-731X E-mail: raul.martins@unesp.br
}

\section{RESUMO}

A violência trouxe uma série de consequências negativas para toda a população, e a escola, como parte da sociedade, não poderia fugir desta situação e, embora os Ministérios da Educação e da Saúde preconizem atividades educativas preventivas sobre violência, estas ainda são incipientes no ambiente de sala de aula. Partindo de uma abordagem comportamental, o objetivo deste trabalho foi verificar se a intervenção educativa na disciplina de Arte, no Ensino Fundamental I, voltada para a prevenção de violência escolar e bullying, contribuiu para o conhecimento e aprendizagem dos participantes, alunos do 5 o ano do Ensino Fundamental. O local da pesquisa foi uma Escola Municipal de Ensino Fundamental I de uma cidade de pequeno porte do interior paulista, sendo um estudo quase experimental, descritivo e interventivo. Os procedimentos envolveram o levantamento de informações sobre a conduta dos alunos, com a utilização dos registros do livro de ocorrências da escola e elaboração das atividades de um programa de ensino, procurando atender às características dos comportamentos levantados, aplicando a teoria comportamental. Os resultados mostram que o procedimento aplicado foi efetivo, pois os alunos apresentaram altas porcentagens de acertos sobre os conhecimentos trabalhados e passaram a reconhecer as violências com características de bullying. Considera-se que este estudo tenha trazido subsídios para o trabalho de prevenção da violência, especialmente o bullying entre crianças do Ensino Fundamental I.

Palavras-chave: Prevenção. Violência Bullying. Educação. Arte. Ensino fundamental I.

\section{CONTRIBUTIONS OF THE TEACHING OF ART FOR THE PREVENTION OF BULLYING VIOLENCE}

\begin{abstract}
Violence is an issue that has been discussed in our society due to the degree that it has reached that has brought a series of negative consequences for the entire population. The school as part of this society could not escape this situation and, although the Ministries of Education and Health advocate preventive educational activities on violence, these are still incipient in the classroom environment. In this perspective, starting from a behavioral approach, the objective of this work is to elaborate, apply and evaluate a set of activities in the discipline of Art, Elementary School I, focused on the prevention of school violence and bullying. The research site was a Municipal School of Elementary Education in a small city in the interior of São Paulo. The research is a quasi-experimental, descriptive and interventional study. The participants were students in the 5 th year of elementary school $\mathrm{I}$. The procedures involved the collection of information about the behavior of the students, using the records of the school's occurrence book and elaborating the activities of a teaching program. These activities were designed following the procedures of behavioral theory and trying to meet the characteristics of the behaviors raised in the book of occurrences. The results show that the applied procedure was effective, since the students presented high percentages of correct answers about the knowledge worked and began to
\end{abstract}


recognize the violence with characteristics of bullying. It is considered that this study has brought subsidies for the work of prevention of violence, especially bullying among elementary school children.

Keywords: Prevention. Violence Bullying. Education. Art. Elementary school.

\section{CONTRIBUCIONES DE LA ENSEÑANZA DE ARTE PARA LA PREVENCIÓN DE LA VIOLENCIA DE BULLYING}

\section{RESUMEM}

La violencia trajo una serie de consecuencias negativas para toda la población, y la escuela, como parte de la sociedad, no podía huir de esta situación y, aunque los Ministerios de Educación y Salud preconizan actividades educativas preventivas sobre violencia, éstas todavía son incipientes en el ambiente de aula. A partir de un abordaje comportamental, el objetivo de este trabajo fue verificar si la intervención educativa en la disciplina de Arte, en la Enseñanza Fundamental I, orientado a la prevención de violencia escolar y bullying, contribuyó al conocimiento y aprendizaje de los participantes, alumnos del 5o año del año Enseñanza fundamental. El lugar de la investigación fue una Escuela Municipal de Enseñanza Fundamental I de una ciudad de pequeño porte del interior paulista, siendo un estudio casi experimental, descriptivo e interventivo. Los procedimientos involucraron el levantamiento de informaciones sobre la conducta de los alumnos, con la utilización de los registros del libro de ocurrencias de la escuela y elaboración de las actividades de un programa de enseñanza buscando atender las características de los comportamientos levantados, aplicando la teoría conductual. Los resultados muestran que el procedimiento aplicado fue efectivo, pues los alumnos presentaron altos porcentajes de aciertos sobre los conocimientos trabajados y pasaron a reconocer las violencias con características de bullying. Se considera que este estudio ha traído subsidios para el trabajo de prevención de la violencia, especialmente el bullying entre niños de la Enseñanza Fundamental I.

Palabras clave: Prevención la violência. Intimidación. La educación. Arte. Enseñanza fundamental I.

\section{INTRODUÇÃO}

A sociedade brasileira apresenta níveis altos de violência (BRASIL, 2019) e suas repercussões podem ser vistas no ambiente escolar, como nas ocorrências de intimidações entre os alunos, nomeadamente o bullying (FANTE, 2005). Esta situação pode ser trabalhada de várias formas, como um projeto global para a escola ou em atividades específicas desenvolvidas dentro das disciplinas. Nesta perspectiva apresentam-se as contribuições do ensino de Arte para a redução de manifestações de bullying entre alunos do Ensino Fundamental.

Ao pensarmos o ensino da Arte lembramos que ele inicia-se no Brasil entre os anos de 1549 e 1808, com a catequização dos povos indígenas pelos Jesuítas, com uma educação rígida até a metade do século XVIII (IAVELBERG, 2003). No século XX ocorreram transformações nas formas de pensar o ensino de arte ou mesmo a produção dos alunos, também influenciados pelas teorias e metodologias exteriores à cultura brasileira (BARBOSA, 2001). Com a Lei de Diretrizes e Bases da Educação Nacional - LDB (BRASIL, 1996) a Arte passa a ser disciplina obrigatória no ensino e, dentre as inúmeras tendências pedagógicas, Barbosa (1991) apresenta a abordagem triangular, que traz uma nova forma de pensar o ensino de Arte.

A primeira dimensão da abordagem triangular é o fazer artístico, a expressão, que tem a função de exteriorizar as experiências artísticas por meio da criação. A segunda se refere ao apreciar, que é feito por meio da leitura das obras de arte e das manifestações culturais, externalizando a fruição que se refere à sensibilização do aluno ao presenciar qualquer tipo de arte, as "impressões" sobre a arte, os pensamentos sobre os assuntos apreciados, a estesia, que se refere à sensibilidade, à emoção e aos sentimentos do aluno. A terceira e última dimensão é a contextualização da arte em seu cotidiano ou no momento histórico em que ocorreu (BARBOSA, 2010).

A violência, para a Organização Mundial de Saúde (OMS), é "O uso intencional da força física ou do poder, real ou em ameaça [...]" (KRUG et al., 2002, p.5), atingindo os sujeitos e Ihes causando "[...] lesão, morte, dano psicológico, deficiência de desenvolvimento ou 
privação" (KRUG et al., 2002, p.5). Falar dela abrange muitas esferas da sociedade, então se optou por focar na escola, pois pesquisas recentes constatam que violência escolar é algo de difícil determinação pelas características escolares. Outro ponto refere-se à própria coleta dos dados, o pesquisador deve ser cuidadoso com os sujeitos participantes por se tratar de uma "ferida" causando maior dor se aludida e não tratada (ZECHI, 2014).

Gonçalves (2011) cita um estudo realizado por Fisher (2010), em nosso país, no qual relata que cerca de $20 \%$ dos alunos presenciam violência em ambiente escolar com alta frequência. Esse dado é alarmante, mostrando a necessidade de trabalhar habilidades específicas para a resolução de problemas que envolvam a violência escolar e diminuam sua ocorrência. Este tema vem sendo foco das grandes organizações mundiais para a formação dos futuros cidadãos do mundo (BRASIL, 2009), e faz parte de diversas políticas brasileiras para a diminuição das ocorrências, pois é intimamente ligado à saúde de sua população (BRASIL, 2009). Neste contexto, a disciplina de Arte pode ser pensada como um meio pelo qual a prevenção das violências pode ser trabalhada, pois entendemos que o tema pode estar inserido nas aulas de qualquer disciplina do ensino regular (BRASIL, 2011), por ele ser um tema transversal, fazendo parte dos conteúdos a serem ensinados na formação dos alunos.

Bullying é uma "[...] palavra de origem inglesa, adotada em muitos países para definir o desejo consciente e deliberado de maltratar outra pessoa e colocá-la sob tensão [...]" (FANTE, 2005, p. 27), e é usado pela área de Psicologia para conceituar comportamentos de agressão e antissociais. Certas características são típicas do bullying, como a repetição prolongada da violência contra uma vítima, que pode ser tanto física como psicológica e sem motivação (FANTE, 2005). Além disso, as pesquisas sobre bullying mostram os mesmos perfis de participantes dessa violência, todos os alunos são participantes de alguma forma, não apenas como vítima e agressor, mas também como espectador.

A prevenção está intimamente ligada à área da saúde, e não é associada ao termo mais amplo dessa pesquisa prevenção de violência. Os Descritores em Ciências da Saúde (Decs) separam o termo, então se associado torna-se um ato para diminuir a ocorrência ou controlar comportamentos agressivos ou violentos contra alguém.

A hipótese da pesquisa investigou se a intervenção na disciplina de Arte poderia favorecer o aprendizado de novos comportamentos de prevenção/proteção em relação à violência e que promovessem o desenvolvimento da criança, com o objetivo de elaborar, aplicar e avaliar um Programa de Ensino na disciplina de Arte no Ensino Fundamental I, voltado para a prevenção de violência escolarbullying e para a promoção do desenvolvimento de habilidades de resolução de problemas positivamente.

\section{DELINEAMENTO METODOLÓGICO}

A pesquisa é um estudo quase experimental (COZBY, 2002) descritivo, por não haver a manipulação de variáveis (ANDERY, 2010, p. 321), além de ser pesquisa básica, pois tem como finalidade "[...] a descoberta ou descrição de conteúdos comportamentais que são selecionados em função de processos comportamentais [...]" em contexto natural.

O local de realização foi uma Escola Municipal de Ensino Fundamental I de uma cidade do interior de São Paulo, com cerca de 15 mil habitantes, em horário letivo, nos dois quintos anos do período vespertino. Participaram 42 alunos do Ensino Fundamental I, quinto ano, seus responsáveis, esclarecidos e ancorados pela assinatura de Termo de Consentimento, constituindo amostra de conveniência (COZBY, 2002), ou seja, amostra não probabilística, escolhida conforme a necessidade da pesquisa e/ou conforme a distribuição feita pela direção da escola, com delineamento de sujeito único, pensando nos resultados individuais (MATOS, 1990) para as mudanças de comportamentos pretendidas na intervenção. O município possui apenas duas escolas municipais de ensino fundamental, as duas escolas se disponibilizaram a serem pesquisadas. Optou-se por fazer a pesquisa na escola sede da professora/pesquisadora no período vespertino em que ela leciona.

Foi elaborado um "Programa de Ensino" com base em material autoinstrutivo de Cortegoso e Coser (2011), partindo da Análise do Comportamento e seus principais autores (SKINNER, 1972, 1982, 2003; VARGAS, 1974; ZANOTTO, 2000; MEDEIROS, 2007; MOREIRA, 2007; CORTEGOSO, 2011; COSER, 2011). Os pressupostos científicos da Análise do 
Comportamento para a educação foram usados e relacionados à Intervenção Prevenção de violência escolar-Bullying. Cortegoso e Coser (2011, p. 10) partem da instrução programada de Skinner segmentando e encadeando o conteúdo de forma a facilitar sua aprendizagem.

A intervenção está dividida em:

- Unidade de ensino 1 - Introdução ao Bullying;

- Unidade de ensino 2 - Desenvolvendo as habilidades de resolução de problemas para o bullying;

- Unidade de ensino 3 - Conhecendo melhor os comportamentos dos participantes do bullying.

Cada unidade possui ao final uma atividade para que o aluno responda de forma a usar os conceitos aprendidos. Partindo da imediaticidade do reforço (SKINNER, 1982), as atividades foram corrigidas no ato de sua feitura para que o aluno pudesse atingir o desempenho esperado, averiguando o que aprendeu e o que pode aprender ainda.

$\mathrm{Na}$ intervenção, optou-se por usar como reforçadores artificiais adesivos de emojis, sendo entregues aos alunos para cada atividade se fosse alcançado o objetivo pelo aluno, por serem mais próximos da realidade tecnológica dos alunos e por exprimirem sentimentos pertinentes a situações de violência vivenciadas na escola.

As atividades foram desenvolvidas levando em consideração os aspectos a seguir:

- Repertório da população à qual se destina o programa (a atividade deve ser adequada à população);

- Possibilidade real de oferecer as condições previstas (em termos dos recursos disponíveis);

- Proximidade da atividade proposta com o meio natural em que o comportamento deve ocorrer (a atividade deve ser mais próxima possível de uma situação natural);

- Eventual necessidade de decomposição de alguns elos excessivamente complexos (com relação às partes funcionais ou respostas) para programação atividades de ensino (CORTEGOSO; COSER, 2010, p. 172).

As atividades foram feitas de forma a se adequar o grau de dificuldade à idade dos alunos; os recursos disponíveis puderam oferecer as condições previstas para as atividades como o uso de tecnologia, materiais plásticos, cartazes, papéis, adereços e o espaço físico, além de estarem no meio natural onde os comportamentos ocorrem, ou seja, a própria escola. Após a primeira unidade, os conteúdos trabalhados foram decompostos para melhor aprendizagem dos alunos. Além de tudo, as atividades foram programadas em minutos predeterminados em uma hora-aula, ou seja, 50 minutos, mas respeitando o ritmo dos alunos, elas foram prolongadas ou até mesmo continuaram nas próximas unidades.

Considerando o uso de uma técnica empregada na área de terapia comportamental aplicada, foi usado como atividade teatral " $\mathrm{O}$ role-playing, que é uma técnica com origem no psicodrama, entretanto tem sido empregada por terapeutas e pesquisadores à luz de outras abordagens teóricas (DEL PRETTE; DEL PRETTE, 1999/2001; OTERO, 2004) para alcançar objetivos psicoeducativos e terapêuticos" (SOUZA; ORTI; BOLSONI-SILVA, 2012, p.105), onde os autores explicitam ser role-playing ou ensaio comportamental.

Caballo (1996, p. 377) descreve que o ensaio comportamental é um procedimento de representação de um problema, no caso para o paciente, e em se tratando dessa pesquisa, para os alunos participantes, para que eles aprendam a "[...] modificar modos de respostas não adaptativas, substituindo-as por novas respostas". Assim, em conformidade com as descrições de Caballo (1996), as cenas serão curtas com as problemáticas devidamente limitadas para que as respostas sejam breves também.

Após apresentação do projeto aos dirigentes da Coordenadoria Municipal de Educação do município em que se localiza a escola estudada e sua aprovação, foi posteriormente submetido ao Comitê de Ética em Pesquisa da Faculdade de Filosofia e Ciências da Universidade Estadual Paulista (FFC/UNESP), que o aprovou em 05/02/2018, sob o número 2.485.110. 
Mediante a aprovação do Comitê de Ética, foram realizados os seguintes procedimentos:

- levantamento de informações sobre a escola, turmas, número de alunos em cada sala, número de meninos e meninas e suas faixas etárias;

- aplicação da intervenção educativa em sala de aula, por meio da arte, durante as aulas de Arte, para ampliação dos conhecimentos dos alunos sobre bullying, inspeção e ajustes das unidades e atividades.

\section{RESULTADOS E DISCUSSÃO}

A intervenção se caracterizou como estudo piloto, feito em pequena escala para verificar se os procedimentos são eficazes como pretendido (COZBY, 2003). No primeiro dia da intervenção educacional, dos 22 participantes da turma I, cerca de dois alunos faltaram, participando 20 na primeira atividade escrita de conhecimentos prévios sobre situações de bullying na escola, mostrando que $75 \%$ dos participantes reconhecem possíveis cenas de bullying e possuem conhecimento sobre esse assunto, os outros $25 \%$ obtiveram um acerto, dois acertos e um erro e três acertos e um erro, confundindo no desenho as situações possíveis de serem bullying (CARTOON NETWORK, 2013).

No primeiro dia da intervenção educacional, dos 20 participantes da turma II, cerca de dois alunos faltaram, participando 18 na primeira atividade escrita de conhecimentos prévios sobre situações de bullying na escola, mostrando que $90 \%$ dos participantes reconhecem possíveis cenas de bullying e possuem conhecimento sobre esse assunto, os outros $10 \%$ obtiveram três acertos e um erro, confundindo no desenho as situações possíveis de serem bullying.

Na segunda unidade de ensino, foram trabalhadas as habilidades de resolução positiva de problemas e habilidades teatrais, como a expressão corporal e facial, em ambas as turmas os alunos ficaram "empolgados" por se tratar de uma atividade prática, de movimentação no espaço da sala de aula.

Mesmo assim, as aulas de Arte não disponibilizam de tempo suficiente para inserir a habilidade dos jogos teatrais a longo prazo, tornando difícil a execução de exercícios teatrais durante a intervenção, pois "à medida que interioriza essas habilidades e essa liberdade ou espontaneidade" o aluno "se transforma em um jogador criativo" (KOUDELA, 2001, p.43), o que significa, dentro da Análise do comportamento, que aos poucos ele consegue usar o repertório aprendido.

Nas duas turmas houve a necessidade de trabalhar as habilidades de jogos teatrais, pois possuem dificuldades de localização/deslocamento no espaço e percepção do próprio corpo no espaço. Trabalhar a habilidade de concentração foi necessário devido à ocorrência de comportamentos como agitação e dispersão que acabou provocando colisões entre alunos, levando à discussão e à briga, resolvidas pela pesquisadora. A desatenção no momento das instruções transmitidas pela pesquisadora, fez com que esses conflitos acontecessem, assim tomou-se cuidado maior em enfatizar que os alunos não poderiam ter contato corporal.

Com a leitura do texto sobre Quem é quem no bullying (FANTE, 2005), todos os alunos demonstraram corporalmente como cada participante do bullying se comporta, atingindo o padrão de desempenho esperado da unidade de ensino. Essa habilidade foi avaliada visualmente.

$A$ atividade de encenação relacionada à primeira atividade da unidade 1 foi executada usando as características aprendidas sobre vítima, agressor e espectador (FANTE, 2005; STELKO-PEREIRA, 2012). Os alunos que assistiam aos colegas atuarem, intervinham nas cenas de forma a tentarem resolver os problemas de bullying conforme orientação da pesquisadora. As duas turmas evidenciaram a atuação da equipe gestora para acabar com a violência entre os alunos, mostrando que a afirmação de Fante (2005) sobre a escola como um todo, que deve participar ativamente na resolução desse problema, é verdadeiramente importante para os alunos, devendo ser mais efetiva no local de pesquisa.

Na terceira unidade de ensino, os alunos conheceram melhor os comportamentos dos participantes do bullying com a brincadeira do detetive. Esta brincadeira contribuiu na construção do repertório para a próxima atividade escrita sobre as características comportamentais principais de ocorrência do bullying.

As respostas da atividade escrita sobre as características principais da violência bullying foram tabuladas e obtiveram a seguinte porcentagem na primeira questão, sendo que a 
resposta correta era "muitas vezes" (Figuras 1 e 2).

Figura 1. Atividade Unidade 3 - Turma

Para que se trate de bullying, essas situações deveriam acontecer:

- Uma vez = Duas vezes = Muitas vezes

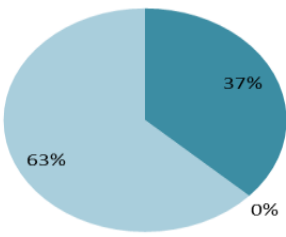

Fonte: Autora (2019).

Figura 3. Atividade Unidade 3 - Turma I

Para que seja bullying, o menino, a menina ou o grupo que agride:

- tem intenção de magoar $=$ faz semperceber $=$ faz por brincadeira

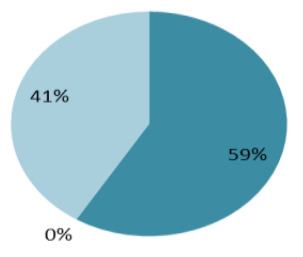

Fonte: Autora (2019)

Na terceira pergunta, a resposta correta era "sente-se mal, discriminado(a) ou humilhado(a)". Foram obtidas as seguintes respostas, que estão expostas nas figuras 5 e 6.

$\mathrm{Na}$ última atividade, os participantes escreveram suas histórias de bullying na escola, enquadrando nas características abordadas na

Figura 5. Atividade Unidade 3 - Turma I

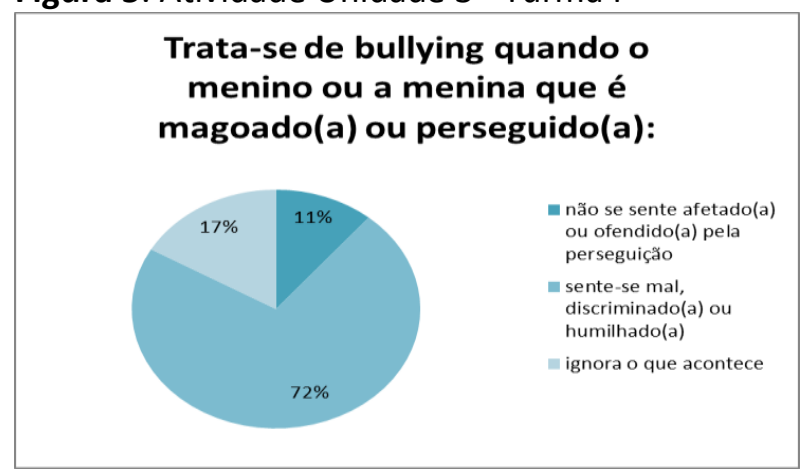

Fonte: Autora (2019).
A segunda questão possuía a resposta "tem intenção de magoar" como correta, as porcentagens foram expostas nas figuras 3 e 4 .

Figura 2. Atividade Unidade 3 - Turma II

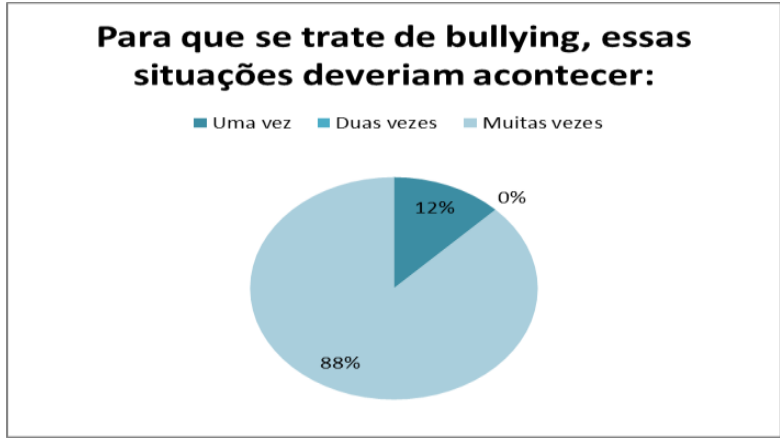

Fonte: Autora (2019).

Figura 4. Atividade Unidade 3 - Turma II

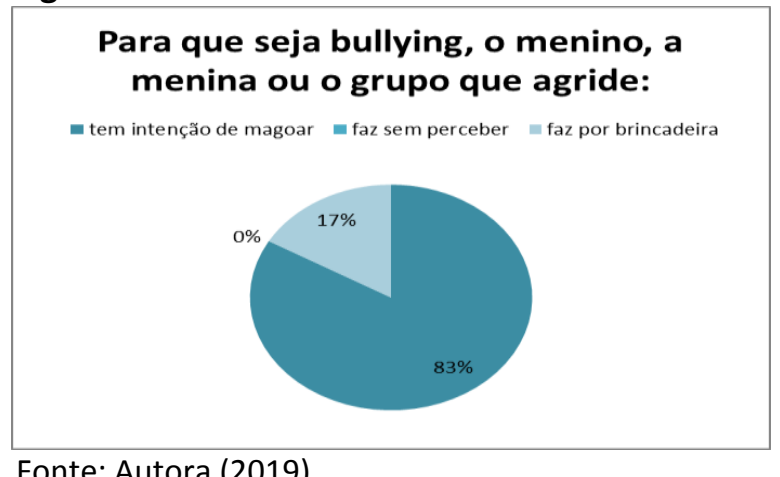

segunda atividade da unidade 3 , pensando se ocorreram muitas vezes, sentiram-se magoados e tiveram intenção de magoar, foram vítimas, agressores ou espectadores. As respostas foram categorizadas e obtiveram o seguinte montante, exposto nas figuras 7 e 8 .

Figura 6. Atividade Unidade 3 - Turma II

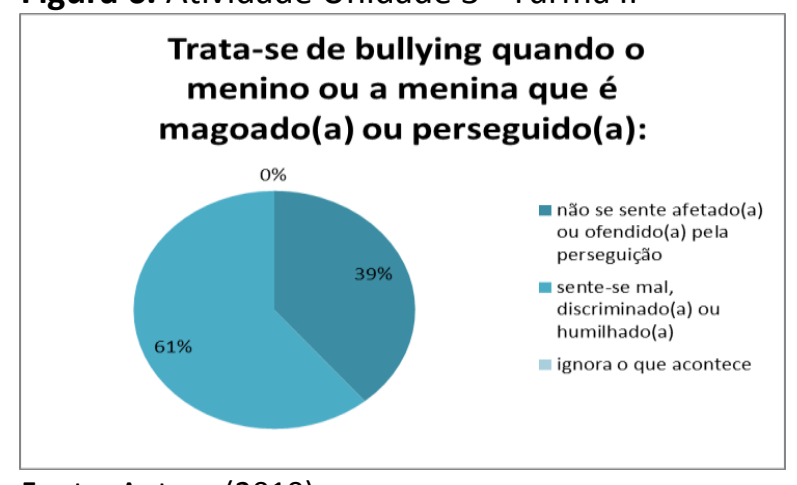

Fonte: Autora (2019). 
Figura 7. Atividade Unidade 3 - Turma I

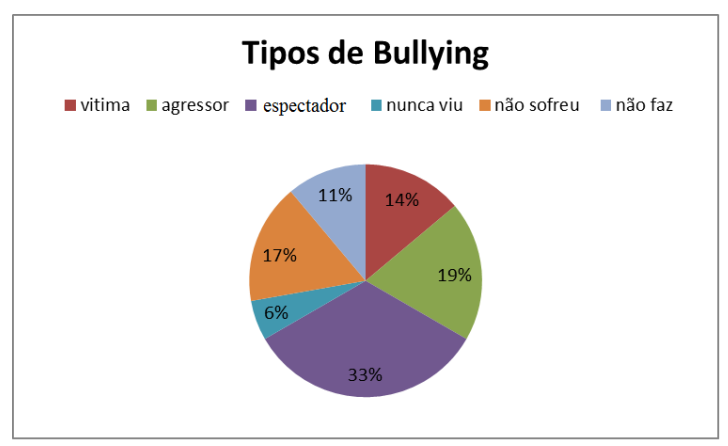

Fonte: Autora (2019).

Esta atividade foi executada de maneira global, os participantes não colocaram seus nomes, apenas escreveram suas experiências. A visão dos alunos sobre a violência bullying e sua prática na escola ainda é paradoxal. Como pesquisadora/professora que atua há quatro anos com os mesmos alunos participantes da pesquisa, observei e presenciei bullying entre os alunos das duas turmas. Na turma II, onde ninguém se colocou como agressor, há pelo menos dois agressores, verificando nos escritos dos alunos, nos quais relataram o nome do colega praticante de bullying, e as formas como se comporta.

Fante (2005) fala dos passos para intervir e prevenir o bullying na escola, sendo a primeira etapa conhecer a realidade escolar, e o primeiro passo ter o compromisso de mudar na medida do possível essa realidade de violência. Assim a intervenção/piloto se caracteriza como conscientizadora e investigadora da realidade escolar. Fante (2005) deixa claro que a escola deve ser ativa na participação de combate à
Figura 8. Atividade Unidade 3 - Turma II

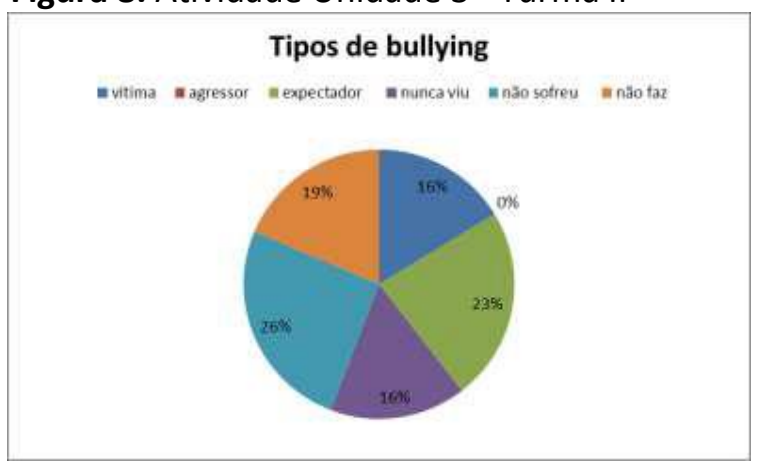

Fonte: Autora (2019).

violência. Mas durante a intervenção a escola não foi inserida devido ao curto tempo de aplicação. Mesmo assim, a pesquisadora/professora reconheceu (segundo passo para combater o bullying, segundo Fante (2005) as mazelas específicas dos participantes do 5o ano do Ensino fundamental do local de estudo.

Por conseguinte, houve o trabalho com conteúdos transversais, os quais são necessários para a formação das habilidades pessoais e sociais da criança, além disso reconhece-se a responsabilidade de prevenir o bullying ou qualquer outra forma de violência escolar (FANTE, 2005).

\section{CONHECIMENTO PÓS INTERVENÇÃO/PILOTO}

A análise individual das duas turmas investigadas está exposta nas tabelas 1 e 2 , com os escores das duas atividades escritas e a soma total delas. Os alunos faltantes ou que não participaram da atividade receberam o valor zero, e os alunos transferidos a sigla TR. 
Tabela 1. Características dos alunos da Turma I e pontuação nas atividades

\begin{tabular}{cllccc}
\hline $\mathrm{Nr}$ & Sexo & Idade & Acertos problemas no pátio & Acertos quando é bullying & Total de pontos \\
\hline 1 & $\mathrm{M}$ & 10 & 3 & 2 & 5 \\
2 & $\mathrm{M}$ & 10 & 0 & 2 & 2 \\
3 & $\mathrm{~F}$ & 10 & $\mathrm{TR}$ & $\mathrm{TR}$ & $\mathrm{TR}$ \\
4 & $\mathrm{~F}$ & 10 & 3 & 2 & 5 \\
5 & $\mathrm{~F}$ & 11 & 3 & 2 & 5 \\
6 & $\mathrm{M}$ & 11 & 3 & 3 & 6 \\
7 & $\mathrm{~F}$ & 10 & 1 & 2 & 3 \\
8 & $\mathrm{M}$ & 10 & 3 & 0 & 3 \\
9 & $\mathrm{M}$ & 10 & 3 & 2 & 5 \\
10 & $\mathrm{~F}$ & 11 & 3 & 1 & 4 \\
11 & $\mathrm{~F}$ & 11 & 3 & 1 & 5 \\
12 & $\mathrm{~F}$ & 10 & 0 & 2 & 2 \\
13 & $\mathrm{M}$ & 10 & 3 & 0 & 3 \\
14 & $\mathrm{~F}$ & 10 & 3 & 0 & 3 \\
15 & $\mathrm{M}$ & 11 & 3 & 2 & 5 \\
16 & $\mathrm{~F}$ & 10 & 2 & 3 & 5 \\
17 & $\mathrm{~F}$ & 10 & 3 & 0 & 3 \\
18 & $\mathrm{M}$ & 10 & 3 & 2 & 5 \\
19 & $\mathrm{M}$ & 10 & 3 & 2 & 5 \\
20 & $\mathrm{~F}$ & 11 & 3 & 3 & 6 \\
21 & $\mathrm{~F}$ & 10 & 3 & 3 & 4 \\
22 & $\mathrm{M}$ & 10 & 1 & 2 & 5 \\
23 & $\mathrm{M}$ & 11 & 3 & 0 & 3 \\
\hline
\end{tabular}

Fonte: Autora (2019).

Tabela 2. Características dos alunos da Turma II e pontuação nas atividades

\begin{tabular}{cllccc}
\hline $\mathrm{Nr}$ & Sexo & Idade & Acertos problemas no pátio & Acertos quando é bullying & Total de pontos \\
\hline 1 & $\mathrm{M}$ & 10 & 3 & 2 & 5 \\
2 & $\mathrm{M}$ & 10 & 0 & 0 & 0 \\
3 & $\mathrm{M}$ & 10 & 3 & 3 & 6 \\
4 & $\mathrm{M}$ & 10 & 3 & 3 & 6 \\
5 & $\mathrm{~F}$ & 10 & 3 & 1 & 4 \\
6 & $\mathrm{~F}$ & 10 & 3 & 3 & 6 \\
7 & $\mathrm{~F}$ & 10 & 3 & 3 & 6 \\
8 & $\mathrm{M}$ & 10 & 3 & 2 & 5 \\
9 & $\mathrm{~F}$ & 10 & 3 & 3 & 6 \\
10 & $\mathrm{M}$ & 10 & 3 & 2 & 5 \\
11 & $\mathrm{~F}$ & 11 & 3 & 1 & 4 \\
12 & $\mathrm{~F}$ & 11 & 3 & 0 & 3 \\
13 & $\mathrm{~F}$ & 13 & $\mathrm{TR}$ & $\mathrm{TR}$ & $\mathrm{TR}$ \\
14 & $\mathrm{~F}$ & 11 & 3 & 2 & 5 \\
15 & $\mathrm{M}$ & 10 & 3 & 3 & 6 \\
16 & $\mathrm{~F}$ & 10 & 3 & 3 & 6 \\
17 & $\mathrm{~F}$ & 10 & 3 & 3 & 6 \\
18 & $\mathrm{~F}$ & 11 & 3 & 2 & 5 \\
19 & $\mathrm{~F}$ & 10 & 3 & 3 & 6 \\
20 & $\mathrm{M}$ & 10 & 3 & 3 & 6 \\
21 & $\mathrm{M}$ & 10 & TR & TR & TR \\
$\mathbf{2 2}$ & $\mathrm{M}$ & 10 & 0 & 3 & 3 \\
\hline
\end{tabular}

Fonte: Autora (2019). 
A soma da atividade Problemas no pátio demonstrou que os participantes possuíam conhecimento prévio sobre bullying e que adquiriram o conhecimento sobre a forma como acontece o bullying durante a intervenção, respondendo, em sua maioria, corretamente com a resposta a seguir: muitas vezes, tem intenção de magoar, sente-se mal, discriminado(a) ou humilhado(a) (FANTE, 2005; MANZINI, 2013; ALBUQUERQUE, 2014; FRICK, 2016). A pontuação total individual atingiu o objetivo esperado de:

- Inserir novos conhecimentos sobre o bullying para que os participantes da pesquisa pudessem aplicá-los nas atividades de intervenção.
- Promover o reconhecimento das características comportamentais dos participantes do bullying (agressor, vítima, espectador) nas atividades da intervenção.

Os alunos que obtiveram escore menor que quatro, foram os que não participaram de uma das duas atividades que ocorreram durante as duas semanas do mês de novembro de 2018, constando de cinco horas-aulas/dias letivos. Resultados de análise de variância mostram que não ocorrem diferenças significantes devido ao sexo ou turma dos participantes (Tabela 3).

Tabela 3. Média e desvio padrão da pontuação dos participantes por atividade, sexo e turma.

\begin{tabular}{|c|c|c|c|c|c|c|}
\hline & \multicolumn{2}{|c|}{ Acertos pátio } & \multicolumn{2}{|c|}{ Acertos bullying } & \multicolumn{2}{|c|}{ Total de acertos } \\
\hline & $\mathrm{M}$ & DP & $\mathrm{M}$ & DP & $\mathrm{M}$ & DP \\
\hline \multicolumn{7}{|l|}{ Sexo } \\
\hline Feminino & 2,30 & 1,174 & 2,00 & 1,076 & 4,35 & 1,599 \\
\hline Masculino & 2,86 & 0,640 & 1,86 & 1,082 & 4,73 & 1,241 \\
\hline \multicolumn{7}{|l|}{ Turma } \\
\hline 1 & 2,50 & 1,012 & 1,64 & 1,049 & 4,18 & 1,220 \\
\hline II & 2,70 & 0,923 & 2,25 & 1,020 & 4,95 & 1,538 \\
\hline
\end{tabular}

Fonte: Autora (2019).

Cozby (2003) fala da implantação e avaliação de programas, com a intervenção em questão, no ambiente escolar, para implantar ações positivas nesse ambiente, passando por cinco avaliações citadas por Rossi et al. (1999).

A intervenção Prevenção de violência escolar - Bullying pode ser avaliada conforme a metodologia citada por Cozby (2003). Primeiro, há a necessidade de se prevenir a violência escolar bullying, pois o levantamento das pesquisas a respeito do tema mostraram percentuais superiores a $40 \%$ (ALBUQUERQUE, 2014) de ocorrência de bullying entre alunos da faixa etária pesquisada e a análise e categorização do livro de ocorrências do local de pesquisa, mesmo sendo o ano de 2016, demonstrou alta ocorrência de comportamentos relacionados ao bullying.

Segundo: a teoria aplicada é a mais condizente e apropriada para se ter maior eficácia no estudo, conforme Elias (2009). Terceiro: o processo de implantação mostrou a necessidade de melhorar as atividades e aprofundar os conteúdos a serem aprendidos. Mesmo sendo um estudo piloto, demonstrou ser bem aceito pelos participantes pela observação dos mesmos durante a aplicação. Quarto e quinto: a eficiência, assim como já relatado, em intervenções com características comportamentais, para que os participantes adquiram habilidades e comportamentos pretendidos tendo resultados positivos assim como visto nos escores de cada aluno que participou da intervenção. O que os participantes registraram e expressaram, não necessariamente será parte de sua conduta posterior, o ideal seria que os comportamentos passassem a fazer parte de seus repertórios e se repetissem na resolução de conflitos de violência.

Aplicar e avaliar corretamente os participantes usando a metodologia do sujeito único da forma como se deu a intervenção não foi corretamente possível, pois não houve manipulação das variáveis dependentes e independentes, e também nem um pré e pósteste, o que seria o correto a se fazer. Também não foi feito um controle rígido do ambiente e aplicador da pesquisa (COZBY, 2003), pois como a pesquisadora era também professora dos participantes da pesquisa, e aplicou a 
intervenção, isso pode ter influenciado na aprendizagem e respostas dos alunos, sendo uma variável a ser analisada.

O primeiro aspecto seria compreender que o ensino/aprendizagem deve ser importante para o aluno, levando-o a comportar-se de maneira mais eficiente para atingir o objetivo de aprender algo com maior facilidade. Conforme Zanotto (2000), a primeira função do professor é planejar os objetivos e as contingências a serem usadas para que o aluno progrida e aprenda, mudando também o comportamento do professor.

\section{CONCLUSÕES}

Levando-se em conta o que foi observado nesse estudo sobre a utilização da abordagem da Análise do Comportamento para educação, percebe-se que nos aspectos fundamentais para preparo e aplicação de um bom programa de ensino é inquestionavelmente eficaz em seus objetivos de aprendizagem focando nos comportamentos a serem úteis aos participantes da pesquisa, como reconhecer os aspectos físicos do agressor na violência bullying, acima de tudo útil em priorizar os comportamentos do professor em detrimento da aprendizagem do (a) aluno (a), além de promover de forma sistemática a aquisição de novos conhecimentos conforme os conhecimentos anteriormente adquiridos.

Embora a área de Arte preconize o aprendizado dos conteúdos das artes como um meio em si, ela foi utilizada com intuito de promover a aprendizagem de aspectos comportamentais do bullying para a resolução de problemas por meio de exercícios teatrais e jogos cênicos, não deixando de lado o ensino de Arte, pois os participantes apreciaram, produziram e leram (Abordagem Triangular) (BARBOSA, 2010) o que fizeram e o que seus colegas apresentaram de forma crítica na realidade escolar em que se encontravam.

Barbosa (2010) deixa explícito em seus textos que a abordagem triangular deve ser usada e adaptada aos contextos em que se insere, não deixando de considerar a aprendizagem dos conteúdos fundamentais da arte, sendo capaz de ser relacionada e associada a outras teorias e abordagens do ensino, assim como foi feito nessa pesquisa.

Em virtude do pouco tempo de estudo, a intervenção foi extremamente curta, embora tenha revelado que os alunos conseguiram identificar cenas de bullying, possuindo conhecimento prévio sobre essa violência, adquiriram novos conhecimentos sobre a forma como acontece o bullying em ambiente escolar e aprenderam a se expressar por meio da arte.

A violência escolar está explícita em documentos da escola pesquisada, assim como em seu cotidiano, ficando evidente na análise dos dados coletados no livro de ocorrências. As pesquisas científicas dos últimos dez anos mostram ser necessária a inclusão e aperfeiçoamento da equipe escolar para distinção de eventuais casos em que não se trata de bullying, além da necessidade de se trabalhar a violência bullying para que os indivíduos não a cometam, pois ela pode favorecer o aparecimento de sintomas psicológicos e de relacionamento interpessoal durante sua presença e conforme sua duração a longo prazo também (ALBUQUERQUE, 2014).

A hipótese de que a intervenção poderia favorecer $o$ aprendizado de novos comportamentos de prevenção/proteção em relação a violências e que promovam o desenvolvimento da criança em relação aos conteúdos trabalhados foi alcançada, como se pode verificar nos dados coletados. Então planejar uma intervenção com duração a longo prazo no modelo descrito na pesquisa pode produzir mudanças de comportamento e aprendizagem de novos comportamentos, assim como auxiliar na prevenção da violência bullying.

Mesmo tendo participado da intervenção com foco na resolução de problemas de bullying na escola, os alunos podem ainda apresentar comportamentos agressivos e bullying.

Levando-se em consideração o que foi mencionado, essa pesquisa, assim como as demais que falam sobre bullying, possui uma lacuna no quesito de instrumento para verificação de ocorrências de bullying entre os escolares. Ainda não há um instrumento bem elaborado e testado cientificamente que possa comprovar seu grau de fidedignidade para avaliar bullying na escola entre os alunos de todo o país, que possa demonstrar quem são seus participantes (vítima, agressor, espectador) ou sua ocorrência.

Hoje temos a lei no 13.663 de 14 de maio de 2018, que prevê ações de combate e conscientização na escola sobre o bullying, reconhecido como intimidação sistêmica, 
devendo ser trabalhado em sala de aula e pela escola.

Concluindo, a formação continuada do professor foi muitas vezes citada durante a leitura das dissertações, teses e livros de referência bibliográfica usados nessa pesquisa. A formação continuada para todas as áreas do saber, além da formação para se trabalhar o bullying em sala de aula aqui é endossada, por sua importância e relevância no contexto de crescente violência e formação deficitária dos profissionais da educação.

\section{AGRADECIMENTOS}

Os autores declaram não haver qualquer potencial conflito de interesse que possa interferir na imparcialidade deste trabalho científico.

\section{REFERÊNCIAS}

ANDERY, M. A. P. A. Métodos de Pesquisa em Análise do Comportamento. Psicologia USP, São Paulo, v. 21, n. 2, p. 313-342, jun. 2010. Disponível em: http://www.scielo.br/scielo.php?script=sci_arttex t\&pid=S0103-

65642010000200006\&lng=pt\&tlng=pt. Acesso em: 18 de jun. 2019. https://doi.org/10.1590/S010365642010000200006

ALBUQUERQUE, P. P. Trauma e histórico de vitimização na escola: um estudo retrospectivo com estudantes universitários. 2014. 253 f. Tese (Doutorado em Psicologia) - Universidade Federal de São Carlos (UFSCAR), São Carlos, 2014.

BARBOSA, A. M. Arte-Educação no Brasil. São Paulo: Perspectiva, 2010.

BARBOSA, A. M. John Dewey e o Ensino da Arte no Brasil. São Paulo: Cortez, 2001.

BARBOSA. Abordagem triangular no ensino das Artes e Culturas Visuais. São Paulo: Cortez, 2010.

BARBOSA, A M. Redesenhando o desenho: educadores, política e história. São Paulo: Cortez, 2015.

BARBOSA. A imagem do ensino da Arte. São Paulo: Perspectiva, 1991.
BRASIL. Ministério da Educação. Lei no 9.394, de 20 de dezembro de 1996. Brasília, 1996. Disponível em: http://www.planalto.gov.br/ccivil_03/leis/19394. htm. Acesso em: 18 de jun. 2019.

BRASIL. Instituto de Pesquisa Econômica Aplicada. Brasília, 2019. Disponível em: http://www.ipea.gov.br/atlasviolencia/. Acesso em: 18 de Jun. 2019.

BRASIL. Por uma cultura da paz, a promoção da saúde e a prevenção da violência. Brasília: Ministério da Saúde, 2009.

BRASIL. Passo a passo PSE: Programa Saúde na Escola: tecendo caminhos da intersetorialidade. Brasília: Ministério da Saúde, 2011.

CABALLO, V. E. Manual de Técnicas de Terapia e Modificação do Comportamento. São Paulo: Santos, 1996.

COZBY, P. C. Métodos de pesquisa em ciências do comportamento. São Paulo: Atlas, 2002.

CORTEGOSO, A. L; COSER, D. S. Elaboração de programa de ensino: material autoinstrutivo. São Carlos: EDUFSCAR, 2011.

ELIAS, M. A. Violência escolar e implicações para o currículo: o Projeto Pela Vida, Não à violência: tramas e traumas. 2009. $294 \mathrm{f}$. Tese (Doutorado em Educação: Currículo) - Pontifícia Universidade Católica de São Paulo (PUC), São Paulo, 2009.

FANTE, C. O fenômeno bullying: como prevenir a violência nas escolas e educar para a paz. Campinas-SP: Verus, 2005.

FRICK, L. T. Estratégias de prevenção e contenção do bullying nas escolas: as propostas governamentais e de pesquisa no Brasil e na Espanha. 2016. 272 f. Tese (Doutorado em Educação) - Universidade Estadual Paulista, Faculdade de Ciências e Tecnologia (UNESP), Presidente Prudente, 2016.

GONÇALVES, C. C. Concepção e julgamento moral de docentes sobre bullying na escola. 2011. 145 f. Dissertação (Mestrado em Educação). Universidade Federal da Paraíba (UFPB/CE), João Pessoa - PA, 2011. 
IAVELBERG, R. Para gostar de aprender Arte. Sala de aula e formação de professores. Porto Alegre: Artmed, 2003.

KRUG, E. G. et al. (Org.). Relatório mundial sobre violência e saúde. Geneva: Organização Mundial da Saúde, 2002.

KOUDELA, I. D. Jogos Teatrais. São Paulo: Perspectiva, 2001.

MATOS, M. A. Análise Funcional do Comportamento. Estudos de Psicologia, Campinas, v. 16, n. 3, p. 8-18, dez. 1999. Disponível em: http://www.scielo.br/scielo.php?script=sci_arttex t\&pid=S0103-

166X1999000300002\&lng=pt\&tlng=pt. Acesso em: 18 de jun. 2019. https://doi.org/10.1590/s0103166X1999000300002

MANZINI, R. G. P. Bullying no contexto escolar: prevenção da violência e promoção da cultura da paz na perspectiva de adultos e crianças. 2013. 207 f. Tese (Doutorado em Psicologia) Universidade de Brasília (UNB). Brasília, 2013.

MOREIRA, M. B.; MEDEIROS, C. A. Princípios básicos de Análise do Comportamento. Porto Alegre: Artmed, 2007.

SOUZA, V.; ORTI, N.; BOLSONIL-SILVA, A. Roleplaying como estratégia facilitadora da análise funcional em contexto clínico. Revista Brasileira De Terapia Comportamental E Cognitiva, v. 14, n. 3, p. 101-122, 2012. Disponível em: http://www.usp.br/rbtcc/index.php/RBTCC.

Acesso em: 18 de jun. 2019. https://doi.org/10.31505/rbtcc.v14i3.551

STELKO-PEREIRA, A. C. Avaliação de um programa preventivo de violência escolar: planejamento, implantação e eficácia. 2012. $193 \mathrm{f}$. Tese (Doutorado em Psicologia) - Universidade Federal de São Carlos (UFSCAR), São Carlos, 2012.

SKINNER, B. F. Tecnologia do ensino. São Paulo: Herder/EDUSP, 1972.

SKINNER, B. F. Sobre o behaviorismo. São Paulo: Cultrix/EDUSP, 1982.

SKINNER, B. F. Ciência e Comportamento Humano. São Paulo: Martins Fontes, 2003.
VARGAS, J. S. Formular Objetivos Comportamentais Úteis. São Paulo: EPU, 1974.

ZANOTTO, M. L. B. Formação de professores: a contribuição da análise do comportamento. São Paulo: EDUC, 2000.

ZECHI, J. A. M. Violência e indisciplina em meio escolar: aspectos teórico-metodológicos da produção acadêmica no período de 2000 a 2005. 2008. 147f. Dissertação (Mestrado em Educação). Universidade Estadual Paulista "Júlio de Mesquita Filho" (UNESP). Presidente Prudente, 2008. 